\title{
GIÁM SÁT BIẾN ĐỒI ĐỘ CAO MỰC NƯỚC BẰNG ĐO CAO VỆ TINH RADAR ĐỘ MỞ TỔNG HỢP TRÊN LUUU VỰC SÔNG MÊ KÔNG
}

\author{
NGUYẼ̃N HÀ PHÚ(1), NGUYẼ̃N NGỌC NAM(1) \\ NGUYẼ̃N TRỌNG TRƯỜNG SƠN(2) \\ ${ }^{(1)}$ Cuc Viễn thám quốc gia \\ ${ }^{(2)}$ Truờng Đại học Tài nguyên và Môi truờng Hà Nội
}

\section{Tóm tắt:}

Giám sát biến đổi độ cao mưc nước là vô cùng cần thiết đối với công tác quản lý tài nguyên nước. Hiện nay, việc úng dụng kĩ thuật đo cao vệ tinh radar độ mở tổng hợp SAR (Synthetic Aperture Radar) cho phép nâng cao độ chính xác cũng nhu khả năng theo dõi độ cao mực nước các sông, hồ có kích thước nhỏ hơn. Nội dung của bài báo này là nhằm đánh giá khả năng giám sát biến đổi mục nước trên luu vục sông Mê Kông sủ dụng dũ liệu Jason-3 và Sentinel-3A. Kết quả thử nghiệm cho thấy trong điều kiện thuận lợi độ chính xác của chuỗi biến đổi độ cao mục nước tù đo cao vệ tinh khi so sánh với số liệu thủy văn ngoại nghiệp có thể đạt được tù̀ $0,15 \mathrm{~m}$ đến $0,20 \mathrm{~m}$ tuy nhiên vẫn có nhũng hạn chế nhu hiệu suất trị đo ở khu vục địa hình có độ dốc lớn vào mùa khô thấp và còn tồn tại nhũ̃ng khoảng thời gian dài không có dĩ liệu có giá trị.

\section{Giới thiệu}

Sông Mê Kông là một trong những dòng sông lớn nhất trên thế giới với chiều dài hơn 4.350 $\mathrm{km}$, khởi nguồn từ vùng núi cao Tây Tạng, dọc theo suốt chiều dài tỉnh Vân Nam (Trung Quốc) và chảy qua lãnh thổ Myanma, Lào, Thái Lan, Campuchia trước khi vào Việt Nam rồi đổ ra biển Đông. Lưu vực sông Mê Kông có tổng diện tích là $795.000 \mathrm{~km}^{2}$ với tổng lượng dòng chảy hàng năm đạt xấp xỉ 475 tỷ $\mathrm{m}^{3}$ và lưu lượng trung bình khoảng $15.000 \mathrm{~m}^{3} / \mathrm{s}$ [1]. Con sông là yếu tố quan trọng đảm bảo kinh tế và đời sống sinh hoạt của người dân trên toàn lưu vực vốn chủ yếu dựa vào nông nghiệp cũng như các nguồn lợi lâm nghiệp và thủy sản.

Dòng chảy chính của sông Mê Kông chảy qua các vùng địa hình khác nhau. Trong đó, khu vực từ thượng lưu con sông cho đến Vientiane (Lào) có địa hình bao quanh bởi các vùng núi cao có sườn dốc lớn, dòng chảy vì thế cũng có độ dốc lớn và độ rộng của sông phần lớn chỉ từ vài chục mét đến nhỏ hơn $500 \mathrm{~m}$. Từ Vientiane trở xuống, sông chảy trên địa hình có độ dốc nhỏ hơn và độ rộng của sông được mở lớn hơn trước khi nó chảy vào vùng đồng bằng châu thổ rộng lớn tại Campuchia và Việt Nam, nơi độ rộng của sông có thể lên đến hơn $2 \mathrm{~km}$.

Với tiềm năng lớn về thủy điện, hiện nay trên lưu vực sông Mê Kông, các nước đã và đang tiến hành xây dựng các hồ chứa nước và đập thủy điện để phục vụ nhu cầu phát triển kinh tế. Tại Trung Quốc, trên sông Lan Thương đã hoàn thành một số công trình thủy điện chính như: Cống Quả Kiều (900 MW, 2011), Tiểu Loan (4.200 MW, 2009), Mãn Loan (1.500 MW, 1993), Đại Triều Sơn (1.350 MW, 2003), Nọa Trác Độ (5.850 MW, 2012) và Cảnh Hồng (1.750 MW, 2008). Và trong những năm qua tại khu vực hạ lưu sông Mê Kông, Lào cũng đang có kế hoạch phát triển các đập thủy điện trên dòng chính với đập thủy điện Xayaboury (1.260 MW) đã hoàn thành trong năm 2019, và đang 
tiến hành xây dựng các đập thủy điện như: Don Sahong (260 MW), Pak Beng (1.320 MW) cũng như quy hoạch một số đập thủy điện khác. Campuchia cũng tuyên bố sẽ xây dựng hai đập thủy điện trên dòng chính là Stung Treng (980 $\mathrm{MW})$ và Sambor (2.600 MW). Việc phát triển thủy điện dòng chính được đánh giá là có tác động tiêu cực đến toàn bộ lưu vực sông như làm thay đổi lưu lượng dòng chảy tự nhiên, ngăn chặn vận chuyển phù sa và ảnh hưởng đến môi trường sinh sống của các loài thủy sản. (Xem hinh 1)

Đối với lĩnh vực quan trắc tài nguyên nước, đo cao vệ tinh radar đã được ứng dụng một cách rộng rãi trên thế giới để nghiên cứu thủy văn lục địa như sông, hồ và các vùng đất ngập nước lớn. Kỹ thuật này được sử dụng trong việc xác định độ cao mực nước, tính toán lưu lượng và trữ lượng nước. Ưu điểm của phương pháp là khả năng cung cấp tập dữ liệu toàn cầu và khắc phục những hạn chế của phương pháp thủy văn truyền thống bằng việc tạo ra những trạm "ảo" bổ xung cho hệ thống các trạm thủy văn vốn hạn chế về số lượng, đặc biệt tại những lưu vực các con sông chia thành nhiều nhánh, những khu vực khó tiếp cận hay các khu vực ngoài biên giới thiếu số liệu quan trắc thủy văn ngoại nghiệp.

Gần đây, những thành tựu trong việc ứng dụng kỹ thuật radar độ mở tổng hợp SAR trong đo cao vệ tinh đã tạo nên một thế hệ vệ tinh mới có độ phân giải cao là Jason-3 và Sentinel-3 nối tiếp tương ứng các dòng thế hệ vệ tinh độ phân giải thấp trước đó là Topex-Poseidon/Jason1/Jason-2 và ERS-1/ERS-2/ENVISAT/SARAL. Thế hệ vệ tinh độ phân giải cao này với ưu điểm là có diện tích chiếu xạ mặt đất (footprint) nhỏ với kích thước xấp xỉ $300 \mathrm{~m}$ (so với kích thước $1,7 \mathrm{~km}$ của vệ tinh độ phân giải thấp) theo hướng

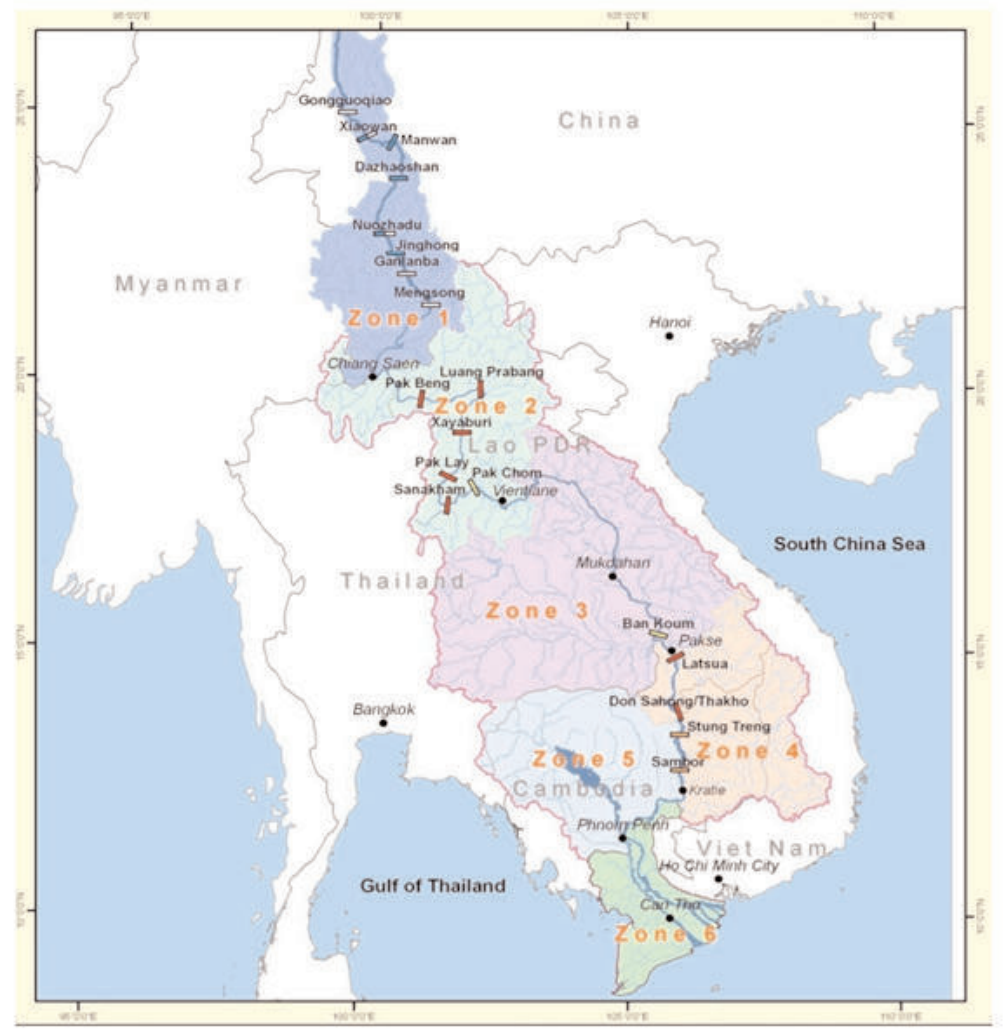

Hình 1: Lưu vực sông Mê Kông và vị trí các hồ chứa nước trên dòng chính 
vệt quỹ đạo vệ tinh nên cho phép hạn chế ảnh hưởng của tín hiệu phản hồi từ mặt đất góp phần tăng cường độ chính xác và khả năng đo cao mực nước của các sông, hồ có kích thước trung bình và nhỏ. Nội dung của bài nghiên cứu này nhằm đánh giá khả năng giám sát biến đổi độ cao mực nước của các vệ tinh Jason-3 và Sentinel-3 dựa trên kết quả đo cao mực nước sử dụng số liệu đo cao vệ tinh tại một số vị trí trên lưu vực sông Mê Kông bao gồm hồ chứa nước Tiểu Loan (Trung Quốc), hồ chứa nước Xayaboury (Lào) và một vị trí trên lãnh thổ Việt Nam nơi có các vệt quỹ đạo vệ tinh đi qua lân cận trạm thủy văn Mộc Hóa để phục vụ cho việc đánh giá độ chính xác của chuỗi biến đổi độ cao mực nước từ đo cao vệ tinh trên cơ sở so sánh với chuỗi biến đổi độ cao mực nước từ số liệu thủy văn ngoại nghiệp.

\section{Dữ liệu sử dụng}

\subsection{Dũ liệu đo cao vệ tinh}

Dữ liệu đo cao được sử dụng trong nghiên cứu này là dữ liệu được thu nhận bởi các vệ tinh thế hệ mới ứng dụng công nghệ SAR như Jason3 và Sentinel-3. Với vệ tinh Jason-3 là vệ tinh đo cao tiếp theo của vệ tinh Jason-2/OSTM được phóng thành công lên quỹ đạo vào ngày 17/01/2016 trong khuôn khổ chương trình hợp tác quốc tế giữa các đối tác NASA (The United States National Aeronautics and Space Administration) và Cơ quan vũ trụ Pháp CNES (Centre National d'Etudes Spatiales). Mục đích là nhằm đảm bảo sự duy trì liên tục của các vệ tinh Topex/Poseidon, Jason-1 và Jason-2/OSTM để hỗ trợ các ứng dụng liên quan đến các sự cố thời tiết cực đoan, các ứng dụng về khí hậu và hải dương học cũng như cho công tác dự báo. Chu kỳ của quỹ đạo vệ tinh là xấp xỉ 10 ngày. Khoảng cách giữa các vệt quỹ đạo vệ tinh trên mặt đất ở vị trí xích đạo khoảng $354 \mathrm{~km}$ và độ phân giải theo hướng dọc theo vệt quỹ đạo vệ tinh trên mặt đất xấp xỉ 300 m. Dữ liệu Jason-3 được thu thập bao gồm dữ liệu từ chu kỳ 33 đến chu kỳ 144 tương ứng với khoảng thời gian 3 năm từ 2017 - 2019. Tập dữ liệu này được tải về từ AVISO ở mức xử lý L2 tại địa chỉ ftp://ftpaccess.aviso.altimetry.fr/geophysical-datarecord/. Trong khi đó, vệ tinh Sentinel-3 là vệ tinh quan trắc Trái đất được phát triển trong một dự án hợp tác giữa ESA và Liên hiệp Châu Âu thuộc Chương trình Copernicus. Vệ tinh Sentinel-3A đã được phóng thành công lên quỹ đạo vào ngày 18/02/2016 và sau đó là vệ tinh Sentinel-3B vào ngày 25/04/2018 với mục đích để đo địa hình mặt biển, nhiệt độ và màu của bề mặt đất và bề mặt đại dương với độ chính xác và tin cậy cao. Vệ tinh này cũng sẽ hỗ trợ cho các hệ thống dự báo biển cũng như quan trắc môi trường và khí hậu. Chu kỳ của quỹ đạo vệ tinh là xấp xỉ 27 ngày. Khoảng cách giữa các vệt quỹ đạo vệ tinh trên mặt đất ở vị trí xích đạo khoảng $104 \mathrm{~km}$ và độ phân giải theo hướng dọc theo vệt quỹ đạo vệ tinh trên mặt đất xấp xỉ $300 \mathrm{~m}$. Dữ liệu được thu thập tập trung chủ yếu vào dữ liệu vệ tinh Sentinel-3A bao gồm dữ liệu từ chu kỳ 13 đến chu kỳ 53. Tương tự như dữ liệu Jason-3, dữ liệu Sentinel-3A cũng tương ứng với khoảng thời gian 3 năm từ 2017 - 2019. Tập dữ liệu này được tải về từ Copernicus Open Access Hub ở mức xử lý L2 với loại sản phẩm SA_2_LAN được sử dụng cho các ứng dụng nghiên cứu thủy văn lục địa tại địa chỉ https://scihub.copernicus.eu/dhus/\#/home.

\subsection{Anh vệ tinh}

Dữ liệu ảnh vệ tinh quang học là ảnh đa phổ Landsat-8 OLI được sử dụng để chiết tách đối tượng bề mặt nước và xác định các trạm "ảo" là vị trí giao cắt giữa vệt quỹ đạo vệ tinh trên mặt đất với đối tượng mặt nước. Landsat- 8 là vệ tinh quan trắc Trái đất mới nhất trong loạt 8 vệ tinh đã phóng thuộc Chương trình Landsat với hợp tác giữa NASA và Cơ quan Khảo sát địa chất Hoa Kỳ USGS (United State Geological 
Survey). Vệ tinh Landsat-8 được phóng vào ngày 11/02/2013 với quỹ đạo hoạt động là quỹ đạo đồng bộ mặt trời ở độ cao $705 \mathrm{~km}$ trên mặt phẳng quỹ đạo nghiêng $98,2^{\circ}$. Thời gian lặp của vệ tinh là 16 ngày tại vị trí xích đạo. Dữ liệu ảnh Landsat-8 OLI có thể được tải về từ trang EarthExplorer được vận hành bởi Cơ quan khảo sát địa chất Hoa Kỳ USGS tại địa chỉ https://earthexplorer.usgs.gov/.

\subsection{Số liệu quan trắc thủy văn}

Số liệu thủy văn được sử dụng để kiểm định độ chính xác của các trị đo vệ tinh trên cơ sở so sánh chuỗi biến đổi độ cao mực nước từ đo cao vệ tinh với chuỗi biến đổi độ cao mực nước từ số liệu thủy văn. Số liệu thủy văn bao gồm các giá trị độ cao mực nước cơ bản trung bình hàng ngày tại trạm khí tượng thủy văn có vị trí nằm gần với vị trí của vệt quỹ đạo vệ tinh giao cắt với mặt nước của dữ liệu vệ tinh Jason-3 và Sentinel-3A. Trong nghiên cứu này, trạm thủy văn được lựa chọn là trạm Mộc Hóa nằm trên khu vực đồng bằng sông Cửu Long, Việt Nam. Số liệu thủy văn được cung cấp bởi Trung tâm Thông tin và Dữ liệu khí tượng thủy văn. Độ cao mực nước đã được tính chuyển sang Hệ độ cao quốc gia.

\section{Phương pháp}

\subsection{Nguyên lí đo cao vệ tinh}

Đo cao vệ tinh là một trong những phương pháp hiện đại được phát triển để thực hiện các trị đo từ không gian nhằm xác định độ cao bề mặt Trái đất một cách gián tiếp thông qua việc đo khoảng cách từ vệ tinh đến bề mặt. Theo đó, thiết bị đo cao lắp đặt trên vệ tinh phát đi các xung tín hiệu radar cao tần theo phương thẳng đứng có công suất thiết kế về phía bề mặt Trái đất và thu nhận, phân tích các tín hiệu phản hồi. Khi đó, khoảng cách $R$ giữa vệ tinh và bề mặt trái đất có thể được tính dựa vào việc xác định khoảng thời gian lan truyền hai chiều của tín hiệu radar $t$.
Đối với nghiên cứu thủy văn lục địa như sông, hồ hay đất ngập nước, độ cao mực nước được xác định bởi chênh cao giữa độ cao quỹ đạo vệ tinh $(A l t)$ với trị đo khoảng cách $R$ và các số hiệu chỉnh khác nhau bao gồm trễ thời gian khi các xung tín hiệu radar đi qua môi trường khí quyển cũng như ảnh hưởng của thủy triều Trái đất. Biểu thức tính độ cao mực nước được biểu thị như sau [2]:

$W S H=A l t-R+\left[D T C+W T C+I C+T_{s}\right]-G C$

Với $D T C$ là số hiệu chỉnh khúc xạ ở tầng đối lưu khô; WTC là số hiệu chỉnh khúc xạ ở tầng đối lưu ướt; $I C$ là số hiệu chỉnh khúc xạ ở tầng điện ly; $T_{S}$ là số hiệu chỉnh do ảnh hưởng thủy triều Trái đất rắn và $G C$ là số hiệu chỉnh geoid. Trong nghiên cứu này, độ cao mực nước được tính theo công thức trên sẽ được quy chiếu tới mặt EGM2008.

Tại mỗi chu kì đo, giá trị độ cao mực nước có thể được tính bằng cách lấy giá trị trung bình (mean). Độ chính xác của độ cao mực nước trung bình này có thể đánh giá bằng công thức tính phương sai được biểu diễn như trong phương trình dưới đây:

$$
\sigma=\sqrt{\frac{\sum_{i=1}^{n}\left(x_{i}-\bar{x}\right)^{2}}{N}}
$$

Trong đó, $\bar{x}$ là độ cao mực nước trung bình; $x_{i}$ là độ cao mực nước của mỗi trị đo tần số cao và $N$ là số trị đo tần số cao nằm trong phạm vi cửa sổ chữ nhật của một trạm “ảo". Đồng thời, trong quá trình tính toán các trị đo tần số cao có sai số vượt quá hạn sai cho phép 2 sẽ được coi như sai số thô và bị loại bỏ. Các giá trị độ cao mực nước trung bình và phương sai sẽ được tính toán lại sao cho đảm bảo thỏa mãn điều kiện ràng buộc trên.

\section{2. Đo cao vệ tinh $S A R$}

Khác với phương pháp đo cao vệ tinh truyền 
thống bị giới hạn trong từng xung tín hiệu, phương pháp đo cao vệ tinh radar độ mở tổng hợp SAR ứng dụng hiệu ứng trễ tần số Doppler cho phép xử lý đồng bộ tín hiệu phản hồi từ một nhóm các xung tín hiệu phát đi liên tiếp. Khi đó, tại mỗi phần tử trên bề mặt nước ở vị trí thẳng đứng lúc thiết bị đo cao SAR đang di chuyển ngang qua theo hướng dọc theo vệt quỹ đạo vệ tinh, đầu thu tín hiệu sẽ thu nhận được nhiều năng lượng phản hồi hơn tức là phần năng lượng được thu nhận được trong suốt thời gian phần tử trên bề mặt nước này được "nhìn" thấy bởi ăng ten trong quá trình di chuyển. Việc xử lý dữ liệu được thực hiện theo cách như là dữ liệu đang được thu nhận từ một ăng ten độ mở tổng hợp, tương đương với chiều dài của ăng ten được mở rộng thêm dẫn đến việc tăng cường độ phân giải theo hướng dọc theo vệt quỹ đạo vệ tinh và đem lại khả năng xử lý theo hai chiều độc lập là chiều theo hướng vệt quỹ đạo vệ tinh và chiều theo hướng vuông góc với vệt quỹ đạo vệ tinh. Sau quá trình xử lý $\mathrm{SAR}$, kết quả là tại mỗi phần tử quan trắc, diện tích chiếu xạ sẽ là hình chữ nhật có kích thước giảm hơn so với kích thước của diện tích chiếu xạ trong phương pháp đo cao radar truyền thống. Trị đo của đo cao vệ tinh SAR khi đó sẽ ít chịu ảnh hưởng bởi các tín hiệu phản hồi từ bề mặt đất xung quanh hơn nên sẽ cải thiện độ chính xác tốt hơn cũng như có khả năng đo cao mực nước các đối tượng có độ rộng hẹp hơn.

\subsection{So sánh chuỗi biến đổi mục nước tù̀ trị} đo cao vệ tinh với chuỗi biến đổi mục nước tù̀ trị đo thủy văn thục địa

Kết quả tính toán mực nước bằng phương pháp đo cao vệ tinh có thể được kiểm định, đánh giá dựa trên cơ sở so sánh với các trị đo thực địa có độ chính xác cao tại một số trạm thủy văn. Tuy nhiên, việc so sánh giữa trị đo cao vệ tinh và trị đo thực địa tại các trạm thủy văn cũng có những hạn chế nhất định khi mà vị trí của các trạm thủy văn không trùng với vị trí quỹ đạo vệ tinh đo cao cắt qua mặt nước. Do vậy, độ chính xác xác định độ cao mực nước sẽ được đánh giá bằng phương pháp tương đối dựa trên giả thiết rằng biến đổi mực nước giữa các trị đo theo trình tự các chu kỳ của vệ tinh đo cao tương tự với biến đổi mực nước của các trị đo thực địa tại trạm thủy văn lân cận đó. Phương pháp so sánh độ cao tương đối như trên có ưu điểm là loại trừ được ảnh hưởng của các sai số hệ thống không mong muốn như: ảnh hưởng của mặt tham chiếu, ảnh hưởng của gió trên bề mặt nước. Tất cả các trị đo lặp theo các chu kỳ khi đó được so sánh với một chu kỳ được chọn làm tham chiếu để xác định chuỗi biến đổi mực nước. Chuỗi biến đổi mực nước từ trị đo cao vệ tinh này được so sánh với chuỗi biến đổi mực nước từ trị đo thủy văn thực địa để tính toán độ lệch giữa hai chuỗi độ cao. Sai số trung phương RMS được tính từ các giá trị độ lệch này sẽ được dùng để đánh giá độ chính xác xác định chuỗi biến đổi mực nước theo

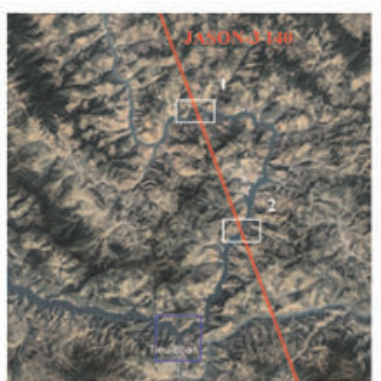

(a)

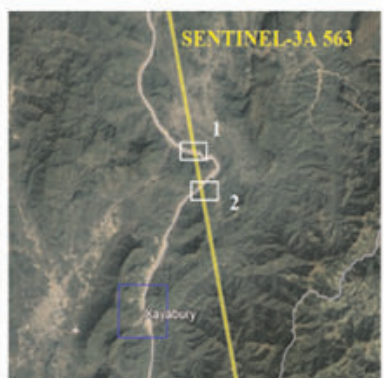

(b)

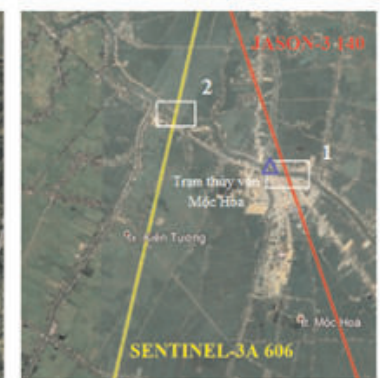

(c)

Hình 2: So đồ vị trí các trạm “ảo”: a) Tiểu Loan, b) Xayaboury và c) Mộc Hóa 
thời gian.

\section{Kết quả và thảo luận}

\section{1. Đánh giá kết quả giám sát biến đổi mục nước}

Sơ đồ vị trí các trạm “ảo” (tức là điểm giao cắt của vệt quỹ đạo vệ tinh với bề mặt nước) được minh họa như trong Hình 2 bao gồm các trạm "ảo" tại hồ chứa nước Tiểu Loan (Trung Quốc), hồ chứa nước Xayaboury (Lào) và tại thị trấn Mộc Hóa (Việt Nam). Trong đó, hồ chứa nước Tiểu Loan có vệt quỹ đạo vệ tinh Jason-3 140 đi qua tại 2 vị trí và hồ chứa nước Xayaboury cũng có vệt quỹ đạo vệ tinh Sentinel3A 563 đi qua 2 vị trí. Trong khi đó, tại khu vực Mộc Hóa có vệt quỹ đạo Jason-3 140 và Sentinel-3A 606 đi qua. (Xem hình 2)

Thông tin khái quát về các trạm "ảo" và kết quả tính toán độ cao mực nước thể hiện bằng sai số trung phương RMS được thống kê như trong Bảng 1 dưới đây. Đánh giá sơ bộ cho thấy sai số trung phương đạt được nằm trong khoảng từ $0,096 \mathrm{~m}$ đến $0,449 \mathrm{~m}$ và hiệu suất của trị đo tức là tỷ lệ phần trăm giữa số trị đo có giá trị trên tổng số chu kì đo đạt được là 58,9\% trong trường hợp nhỏ nhất và lên đến 95,5\% trong trường hợp lớn nhất. Kết quả giám sát biến đổi mực nước tại tất cả các trạm "ảo" này đều thể hiện rõ xu hướng biến đổi mực nước theo mùa và hàng năm. Tại hồ chứa nước Tiểu Loan, do đặc điểm địa hình của khu vực thượng lưu sông Mê Kông được bao quanh bởi các dãy núi cao có sườn dốc lớn nên ảnh hưởng nhiều đến độ chính xác xác định độ cao mực nước. Đồng thời, độ rộng của bề mặt nước cũng là một trong các yếu tố ảnh hưởng chính đến độ chính xác đối với hồ chứa nước Tiểu Loan. Khi so sánh giữa hai vị trí trạm "ảo" có độ rộng là $400 \mathrm{~m}$ và $720 \mathrm{~m}$ thì sai số trung phương đạt được tương ứng là $0,449 \mathrm{~m}$ và $0,360 \mathrm{~m}$ với hiệu suất cũng tương ứng là $58,9 \%$ và $66,1 \%$. Hồ chứa nước Xayaboury nằm gần với phân cách giữa thượng lưu và trung lưu sông Mê Kông nên độ dốc của sườn núi xung quanh đã giảm đáng kể vì thế độ chính xác và hiệu suất trị đo được cải thiện tốt hơn với giá trị tương ứng là 0,110 m và $90,2 \%$ ứng với vị trí trạm “ảo" có độ rộng $700 \mathrm{~m}$ với dữ liệu đo cao vệ tinh Sentinel-3A. Kết quả cuối cùng tại Mộc Hóa cho thấy trong những điều kiện thuận lợi như địa hình bằng phẳng, dòng chảy của sông hướng vuông góc với vệt quỹ đạo vệ tinh thì cả dữ liệu đo cao vệ tinh Jason-3 và Sentinel-3A đều có thể thu nhận được các trị đo đối với bề mặt nước có độ rộng nhỏ hơn $100 \mathrm{~m}$ với sai số và hiệu suất trị đo cũng tương đối tốt. (Xem bảng 1)

Kết quả phân tích chuỗi biến đổi độ cao mực nước theo thời gian cho thấy tại hồ chứa nước Tiểu Loan các trị đo có giá trị chủ yếu tập trung vào khoảng thời gian những tháng mùa mưa trong khi trị đo vào những tháng mùa khô thường bị mất giá trị (Hình 3, ảnh trái trên). Một

Bảng 1

\begin{tabular}{|c|c|c|c|c|c|c|c|c|c|}
\hline $\mathbf{T}$ & Trạm "ảo" & $\begin{array}{l}\text { Dữ } \\
\text { liệu }\end{array}$ & $\begin{array}{l}\text { Vệt } \\
\text { Quỹ } \\
\text { đạo }\end{array}$ & Kinh độ & Vĩ độ & $\begin{array}{c}\text { Khoảng } \\
\text { cách } \\
\text { (km) }\end{array}$ & $\begin{array}{c}\text { Độ } \\
\text { rộng } \\
\text { (m) }\end{array}$ & $\begin{array}{c}\text { RMS } \\
\text { (m) }\end{array}$ & $\begin{array}{l}\text { Hiệu } \\
\text { suất } \\
(\%)\end{array}$ \\
\hline 1 & Tiểu Loan (1) & JA3 & 140 & 100,1114 & 24,9919 & 30,2 & 400 & 0,449 & 58,9 \\
\hline 2 & Tiều Loan (2) & JA3 & 140 & 100,1740 & 24,8543 & 18,8 & 720 & 0,360 & 66,1 \\
\hline 3 & Xayaboury (1) & S3A & 563 & 101,8686 & 19,4202 & 17,0 & 700 & 0,110 & 90,2 \\
\hline 4 & Xayaboury (2) & S3A & 563 & 101,8765 & 19,3864 & 14,0 & 500 & 0,107 & 78,1 \\
\hline 5 & Mộc Hóa (1) & JA3 & 140 & 105,9431 & 10,7786 & & 80 & 0,125 & 95,5 \\
\hline 6 & Mộc Hóa (2) & S3A & 606 & 105,9099 & 10,7937 & & 80 & 0,096 & 70,7 \\
\hline
\end{tabular}


điểm khác cũng cần lưu ý là đối với dữ liệu đo cao vệ tinh Jason-3 trong khoảng thời gian từ đầu năm 2017 (tức chu kỳ 33) đến cuối tháng 8/2017 (tức chu kỳ 57), hiệu suất của các trị đo Jason-3 thường rất nhỏ với một số trường hợp thậm chí gần như bằng không. Đối với trường hợp của hồ chứa nước Xayaboury, dữ liệu độ cao mực nước cũng ghi nhận quá trình tích nước sau khi đã hoàn thành đập thủy điện từ 07/2018 để nâng mực nước trung bình từ $260 \mathrm{~m}$ lên mực nước trên 275 m kể từ đầu năm 2019 (Hình 3, ảnh phải trên). Mực nước này gần như được duy trì trong suốt năm 2019 và chỉ được hạ thấp một phần trong khoảng thời gian ngắn cuối năm. Rõ ràng, quá trình tích nước này đã ảnh hưởng không nhỏ đến tình hình hạn hán gay gắt trong năm 2019 đối với một quốc gia ở khu vực hạ lưu sông Mê Kông như Việt Nam.

Để đánh giá độ tin cậy của dữ liệu đo cao vệ tinh Jason-3 và Sentinel-3A, do hồ chứa nước Tiểu Loan và Xayaboury đều có vệt quỹ đạo vệ tinh giao cắt với mặt nước tại hai vị trí gần nhau nên nếu giả thiết rằng biến đổi mực nước tại hai vị trí đó giống nhau thì khi đó các chuỗi biến đổi độ cao mực nước theo thời gian của chúng sẽ có sự tương quan với nhau. So sánh giữa các chuỗi biến đổi mực nước theo thời gian cho thấy hệ số tương quan giữa các chuỗi biến đổi độ cao mực nước (Hình 3, ảnh dưới) nhận được từ dữ liệu Jason-3 đối với hồ chứa nước Tiểu Loan là $\mathrm{R}^{2}=$ 0,997 trong khi hệ số tương quan giữa các chuỗi biến đổi độ cao mực nước nhận được từ dữ liệu Sentinel-3A đối với hồ chứa nước Xayaboury là
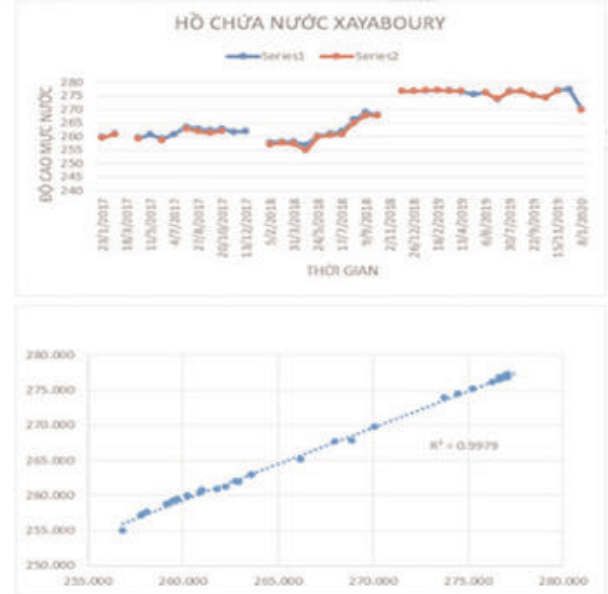

Hình 3: So sánh giũ̃a các chuỗi biến đổi độ cao mục nước theo thời gian tại các trạm "ảo" khu vực hồ chứa nước Tiểu Loan (ảnh trái) và hồ chứa nước Xayaboury (ảnh phải) cùng với hệ số tuoơng quan của chúng (ảnh duới).

Bảng 2: Thống kê số liệu trạm “ảo” và trạm thủy văn được sử dụng trên sông Mê Kông

\begin{tabular}{|c|c|c|c|c|c|c|c|c|c|}
\hline $\begin{array}{l}\mathbf{T} \\
\mathbf{T}\end{array}$ & Trạı & $\begin{array}{l}\text { Dữ } \\
\text { liệu }\end{array}$ & $\begin{array}{l}\text { Vệt } \\
\text { quỹ } \\
\text { đạo }\end{array}$ & $\begin{array}{l}\text { Tọa d } \\
\text { (WG }\end{array}$ & & $\begin{array}{c}\text { Chiều } \\
\text { rộng } \\
\text { sông } \\
\text { (m) }\end{array}$ & $\begin{array}{l}\text { Trạm } \\
\text { thủy } \\
\text { văn }\end{array}$ & $\begin{array}{l}\text { Khoảng } \\
\text { cách đến } \\
\text { trạm thủy } \\
\text { văn } \\
\text { (km) }\end{array}$ & $\begin{array}{r}\text { RMS } \\
\text { (m) }\end{array}$ \\
\hline 1 & Mộc F & JA3 & 140 & 105 & 10 , & 80 & $\begin{array}{l}\text { Mộc } \\
\text { Hóa }\end{array}$ & $\begin{array}{c}0,5 \\
\text { (Hạ lưu) }\end{array}$ & 0,147 \\
\hline 2 & Mộc Hóa (2) & S3A & 606 & 105,9099 & 10,7937 & 80 & $\begin{array}{l}\text { Mộc } \\
\text { Hóa }\end{array}$ & $\begin{array}{c}4,0 \\
\text { (Ha lưu) }\end{array}$ & 0,200 \\
\hline
\end{tabular}




\section{Nghiên cúu - Úng dụng}
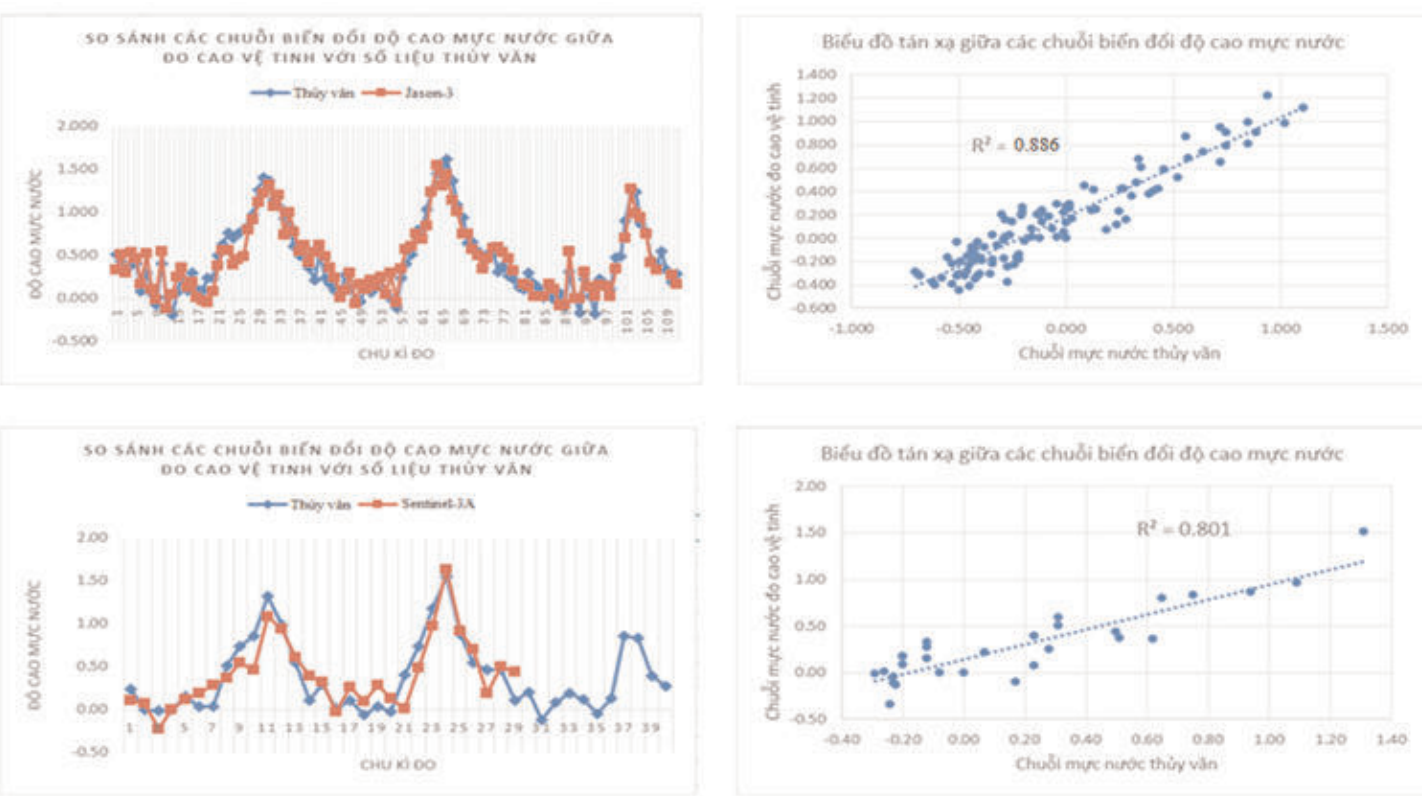

Hình 4: Kết quả so sánh giũa chuỗi biến đổi độ cao mục nước tù đo cao vệ tinh Jason-3 và Sentinel-3A (màu đỏ) với số liệu thủy văn (màu lam) tại trạm thủy văn Mộc Hóa

$\mathrm{R}^{2}=0,998$. (Xem hinh 3)

\section{2. Đánh giá độ chính xác xác định chuỗi biến đổi độ cao mục nước}

Do vị trí của các trạm "ảo" thông thường không trùng với vị trí của trạm thủy văn nên việc đánh giá độ chính xác xác định độ cao mực nước bằng đo cao vệ tinh dựa trên giả thiết rằng biến đổi mực nước tại trạm “ảo" và trạm thủy văn lân cận đó là tương quan với nhau khi đó chuỗi biến đổi độ cao mực nước theo thời gian từ đo cao vệ tinh sẽ được so sánh với chuỗi biến đổi độ cao mực nước theo thời gian từ số liệu thủy văn [3]. Khi đó, chuỗi biến đổi độ cao mực nước từ đo cao vệ tinh được tính dựa trên việc tính toán độ cao mực nước tương đối so với độ cao mực nước tại một chu kì bất kì được lựa chọn làm tham chiếu hoặc độ cao mực nước trung bình. Trong nghiên cứu này, số liệu quan trắc mực nước tại trạm thủy văn Mộc Hóa được sử dụng để đánh giá chuỗi biến đổi độ cao mực nước tại các trạm "ảo" của dữ liệu vệ tinh đo cao Jason-3 và
Sentinel-3A lân cận.

Kết quả kiểm định đánh giá độ chính xác của dữ liệu đo cao vệ tinh Jason-3 và Sentinel-3A tại các trạm "ảo" lân cận trạm thủy văn Mộc Hóa được tổng hợp như trong Bảng 2 dưới đây cho thấy sai số trung phương RMS độ lệch giữa các chuỗi biến đổi độ cao mực nước từ đo cao vệ tinh với số liệu thủy văn có thể đạt được tương ứng xấp xỉ với $0,15 \mathrm{~m}$ và $0,20 \mathrm{~m}$. (Xem bảng 2 )

So sánh giữa chuỗi biến đổi mực nước của vệ tinh Jason-3 140 trên sông Vàm Cỏ Tây với chuỗi biến đổi mực nước từ số liệu thủy văn tại Mộc Hóa, kết quả như Hình 4 (ảnh trên) cho thấy đồ thị của chuỗi biến đổi độ cao mực nước từ đo cao vệ tinh khá khớp với chuỗi biến đổi độ cao mực nước từ số liệu thủy văn với hệ số tương quan giữa hai chuỗi biến đổi độ cao mực nước là khá tốt với $\mathrm{R}^{2}=0,886$. (Xem hình 4)

Bên cạnh đó, so sánh chuỗi biến đổi độ cao mực nước của vệt quỹ đạo vệ tinh Sentinel-3A 606 cũng khá tốt với hệ số tương quan giữa 
chuỗi biến đổi độ cao mực nước từ đo cao vệ tinh với chuỗi biến đổi độ cao mực nước từ số liệu thủy văn tại trạm Mộc Hóa là $\mathrm{R}^{2}=0,801$ (Hình 4, ảnh dưới). Tuy nhiên, đồ thị trên cũng cho thấy hiệu suất trị đo bị ảnh hưởng do giãn cách một khoảng thời gian dài không có số liệu kể từ thời điểm $03 / 2019$. Với trường hợp này hiệu suất của trị đo trước thời điểm 03/2019 đạt $100 \%$ thì sau thời điểm đó hiệu suất trị đo ngược lại chỉ còn là $0 \%$.

\section{Kết luận}

Giám sát biến đổi độ cao mực nước lưu vực sông Mê Kông là vô cùng cần thiết đối với công tác quản lý tài nguyên nước, đặc biệt là khu vực thượng lưu nơi thiếu các số liệu quan trắc ngoại nghiệp. Dữ liệu đo cao vệ tinh radar độ mở tổng hợp SAR đang mở ra cơ hội để theo dõi mực nước các sông, hồ có độ rộng trung bình và nhỏ. Kết quả đánh giá, kiểm nghiệm độ chính xác của dữ liệu đo cao vệ tinh Jason-3 và Sentinel-3A trên khu vực sông Mê Kông cho thấy sai số trung phương độ lệch giữa các chuỗi biến đổi độ cao mực nước thu nhận từ đo cao vệ tinh với chuỗi biến đổi độ cao mực nước thu nhận từ số liệu thủy văn lân cận có thể đạt được trong khoảng
$0,15-0,20 \mathrm{~m}$ trong điều kiện địa hình bằng phẳng. Đối với địa hình bằng phẳng, dữ liệu đo cao vệ tinh Jason-3 và Sentinel-3A có thể giám sát biến đổi mực nước các con sông có độ rộng trung bình nhỏ hơn $100 \mathrm{~m}$. Như vậy, so với các vệ tinh thế hệ cũ như Jason-2 và ENVISAT, rõ ràng các vệ tinh thế hệ mới đã có sự cải thiện đáng kể về độ chính xác cũng như khả năng thu nhận dữ liệu độ cao mực nước của các sông, hồ có kích thước nhỏ hơn. $\bigcirc$

\section{Tài liệu tham khảo}

[1]. Lê Anh Tuấn, Các đập nước và hồ chứa ở thượng nguồn: Có hay không nguy cơ môi sinh tiềm ẩn cho hạ nguồn sông Mê Kông, Hội đập lớn và phát triển nguồn nước Việt Nam.

[2]. Calmant, S., Seyler, F. Crétaux, J.F. 2008, Monitoring continental surface water by satellite altimetry, Surv Geophysics, Vo. 29, pp. 247 269.

[3]. Birkett, C.M. 1998, Contribution of the Topex NASA radar altimeter to the global monitoring of large rivers and wetlands, Water Resour Research, Vol.34, No. 5, pp. 1223 $1239 . \mathrm{O}$

\section{Summary}

\section{Monitoring of water level variations in Mekong Delta Basin using SAR altimeter data}

Nguyen Ha Phu, Nguyen Ngoc Nam

National Remote Sensing Department

Nguyen Trong Truong Son

\section{Hanoi University of Natural Resources and Environment}

Monitoring of water level variations is essential for water resource management. Currently, the application of the Synthetic Aperture Radar (SAR) altimetry technology allows to improve the accuracy as well as the ability to monitor the water level variations of smaller rivers and lakes. The content of this paper is to evaluate the possibility of monitoring water level variations in the Mekong River basin using data Jason-3 and Sentinel-3A. The results show that in comparison with the timeseries of water level variations from the In-Situ hydrological data, the accuracy of the time-series of water level variations from satellite altimeter data can be achieved from $0.15 \mathrm{~m}$ to $0.20 \mathrm{~m}$ under favourable conditions, however, the measurement performance in slope mountainous areas is still limited in dry season and the cycles with no valid data are sometimes in long periods of time. $\mathrm{O}$ 